\title{
A CRIANÇA E O CONSUMO SUSTENTÁVEL: UMA ABORDAGEM DA CONSTRUÇÃO MIDIÁTICA DA SUBJETIVIDADE NO CONTEXTO AMBIENTAL
}

\author{
Isabelle Bezerra Bem ${ }^{1}$ \\ Hommel Pinheiro Lima
}

\begin{abstract}
RESUMO
As mudanças nos padrões organizacionais, que primam por políticas de certificação ambiental cada vez mais rígida, visando à preservação do meio ambiente, esquecem, por vezes, da educação para o consumo. A expansão do consumo alcança patamares maiores a cada ano, sendo impossível desvincular a prática do consumo do cotidiano dos jovens. Entretanto deve-se compreender a prática de consumir não como nociva, mas passiva de adequação ao cenário atual de escassez de recursos primários. Buscou-se compreender de que forma a Cultura das mídias impacta nas decisões pertinentes ao consumo de bens e serviços relacionados ao público infantojuvenil e qual a percepção desses indivíduos em relação as implicações ao meio ambiente. É neste contexto, que se apresenta o objetivo geral desta pesquisa: verificar a influência da mídia e da escola formal na construção do consumidor infantil e sua conscientização ambiental. Para tanto lançou-se mão de método exploratório e descritivo, com delineamento quantitativo a partir da aplicação de um questionário misto com 194 estudantes de escolas públicas e privadas. Aponta-se como principal resultado o fato de que a escola se torna ferramenta fundamental na educação dos consumidores que se encontram imersos em teias ilusórias tecidas pela publicidade e reforçadas pelos grupos sociais e seus símbolos. O esclarecimento e direcionamento desse público jovem deve ocorrer dentro da escola, a qual necessita desenvolver nos alunos uma visão holística dos indivíduos e do meio em que vivem, sendo possível a formação de consciência e atitudes preconizadas na avaliação de ações críticas, em prol da sustentabilidade ambiental.
\end{abstract}

Palavras-chave: Cultura. Comunicação. Consumo. Subjetividade. Infantojuvenil.

Recebido em: 31/03/2016 | Aceito em: 02/08/2016

\footnotetext{
${ }^{1}$ Bacharel em Administração pela Faculdade Paraíso do Ceará, membro do grupo de pesquisa em consumo e cibercultura da Univerisade Federal da Paraíba. E-mail: bell.bb@hotmail.com

${ }^{2}$ Bacharel em Administração de Empresas - Universidade de Fortaleza (1989). Mestre em Psicologia - Programa de Pós-Graduação em Psicologia da Universidades de Fortaleza (2013) e Especialista em Gestão Empresarial e Negócios - Faculdade Unichristus (2006). Coordenador de pesquisa e professor titular do curso de Bacharelado em Administração e do curso Tecnólogo em Marketing da Faculdade Paraíso do Ceará (FAP). Coordenador do Núcleo de Estudos sobre Cultura, Consumo e Trabalho. E-mail: hommellimaa3@gmail.com
}

Ciência e Sustentabilidade - CeS | Juazeiro do Norte v. 2, n. 1, p. 56-81, jan/jun 2016 I ISSN 2447-4606 


\section{INTRODUÇÃO}

Tomar decisões é uma ação corriqueira do indivíduo, influenciada por estímulos internos e externos. Nessa essa visão, logo após sofrer uma tensão, o indivíduo desenvolve uma necessidade que projeta o seu estado atual. Esse, então, toma atitudes em busca de liberar esta tensão e como consequência alcançar a satisfação dessa necessidade. Entretanto, nem sempre é possível obter a satisfação.

Desse modo, segue-se um ciclo sempre voltando a um estado de equilíbrio (ou não) para se iniciar todo o processo novamente, sem ao menos perceber quando ele começa ou termina, ou até mesmo não identificando os agentes motivacionais existentes por trás desses ensejos ou necessidades que se julga, muitas vezes, intrínsecos a nós (SAMPAIO, 2009).

Essa sucessão de acontecimentos faz parte do processo construtivo de identificação dos indivíduos com os elementos constitutivos da cultura: os signos, os meios de comunicação, os mitos, os fatos e atos marcantes, podendo se estabelecer através do consumo e suas implicações comunicacionais. Em tudo existem as trocas de experiências do consumo, não se pode desvincular a vida humana em sociedade desse ato comum, praticado constantemente por todas as pessoas em diferentes estágios da vida, em maior ou menor escala (MORIN, 2000; SANTAELLA, 2003).

Este trabalho é justificado a partir da importância do estudo do consumo infanto-juvenil e suas relações com as mídias, sendo uma referência a um conjunto de pessoas ligadas através de relacionamentos sociais, motivadas pela relação de consumo, pela cultura de massa, ou até mesmo por compartilhamento de sentimentos e através dessas referidas ligações no processo de construção e/ou reconstrução de sua estrutura social.

Percebe-se que este mesmo processo ocorre com crianças de todas as idades e classes sociais. Entretanto, há cooperação entre a mídia e a educação formal na construção da subjetividade infantil enquanto consumidor consciente, do ponto de vista da sustentabilidade ambiental? O consumo é compreendido como parte do processo de reconhecimento estruturativo do indivíduo, promovendo diversos estímulos aos jovens consumidores e, por conseguinte incutindo nesses as impressões das mídias de massa (CAMPBELL, 2007; MORIN, 2000). 
Observa-se, portanto, a mídia como instrumento operante da realidade, podendo influir na percepção do jovem e da criança, enquanto consumidores, em relação ao produto ou serviço ofertado. O estado tenta mediar essas trocas de informações levando em conta os direitos básicos da criança e do adolescente, que obriga o veiculador da mídia a censurar os conteúdos que ferem estas prerrogativas básicas: apologia à violência, drogas, álcool e conteúdos sexualmente explícitos.

O consumidor infantojuvenil, como sujeito supostamente mais vulnerável que os demais, levando em consideração as poucas ferramentas que the são próprias para distinguir o lúdico e utópico do real e factível, necessita de maior atenção na sua exposição ao que se veicula, em propósito de incitar nesse público a efetivação do consumo. Nota-se ainda, que, durante a construção social deste indivíduo, o consumo não deve deter papel determinante, podendo ter seu caráter de singularidade perceptiva deformado por fatores que propagam o egocentrismo e individualismo e a ausência da consciência ambiental.

Os processos comunicacionais guardam grande protagonismo na constituição referida desses jovens consumidores, uma vez que é por meio deles que se elaboram as relações de intermediação do consumo. Por esse motivo torna-se necessário apropriar-se da taxonomia de terminologias e definições destes aspectos, a fim de se compreender tais inter-relações.

Essa pesquisa vem enriquecer o contexto de estudo acadêmico, de modo a intertextualizar diferentes correntes de estudo. Levando à assimilação de singularidades sociais num contexto regional, abordando, ao mesmo tempo, uma temática de relevância global. No âmbito social, as contribuições relacionam-se à compreensão e desenvolvimento da comunidade local. Auxiliando no apuração e percepção dos fenômenos que impactam o desenvolvimento social.

O objetivo desse trabalho é, portanto, compreender de que forma a Cultura das mídias impacta nas decisões pertinentes ao consumo de bens e serviços relacionados ao público infanto-juvenil, verificando qual a percepção desses indivíduos em relação às implicações ao meio ambiente.

O presente estudo está distribuído da seguinte maneira: após o tópico introdutório, são apresentados os principais recortes temáticos da pesquisa envolvendo o desenvolvimento social da infância, a discussão conceitual do consumo e o meio ambiente em correlação com a educação para o consumo. Em 
seguida, apresenta-se o apanhado metodológico utilizado como delineamento dessa pesquisa, os resultados obtidos e as conclusões relacionadas aos aspectos teóricos.

\section{REFERENCIAL TEÓRICO}

\subsection{A dissolvência da infância}

A partir do telégrafo surge a indústria da notícia e seus meandros, não mais havendo portadores de notícias, o sujeito torna-se vago, despersonalizando a figura do emissor. A informação torna-se anônima, indébita, e, acima de tudo, atual, não mais importando as informações pretéritas. Esses atributos da nova informação possibilitaram a produção da comunicação escalar em virtude da velocidade com que se pode reproduzir (MCLUHAN, 1974).

Toda essa nova tendência à comunicação modifica o cenário da infância que carece de um modelo singular em que o ato de comunicar é manipulado tãosomente por adultos. Os meios que permitem uma assimilação cognitiva de rápida absorção foram desenvolvidos, e a informação passa a chegar à criança indiscriminadamente. Entretanto, o que diferencia essa informação é essencialmente sua composição estrutural e de recepção (MORIN, 2000). A esse respeito, Bourdieu (1997) menciona o conceito de ideias feitas ${ }^{3}$, as quais já se encontram num estado de banalização e tornam facilmente aceitas, visto que o critério de recepção se encontra preenchido, não existindo a necessidade de o receptor assimilar o conhecimento, já que encontra-se previamente dissolvido, por meio das múltiplas imagens e cores que efetivam os fatos, ainda que não se trate de verdades irrevogáveis. A esse respeito Mcluhan (1974, p. 64, grifo do autor) destaca:

Contemplar, utilizar ou perceber uma extensão de nós mesmos sob forma tecnológica implica necessariamente em adotá-la. Ouvir rádio ou ler uma página impressa é aceitar essas extensões de nós mesmos e sofrer o "fechamento" ou o deslocamento da percepção, que automaticamente se segue. Incorporando continuamente tecnologias, relacionamo-nos a elas como servomecanismos. Eis por que, para utilizar esses objetos-extensõesde-nós-mesmos. Devemos servi-los, como a ídolos ou religiões menores. Um índio é um servomecanismo de sua canoa, como o vaqueiro de seu cavalo e um executivo de seu relógio.

\footnotetext{
${ }^{3}$ Conceito desenvolvido por Floubert, mencionado no livro de Bourdieu, Sobre a televisão, 1997.
}

Ciência e Sustentabilidade - CeS | Juazeiro do Norte v. 2, n. 1, p. 56-81, jan/jun 2016 
A reação necessária à compreensão da imagem diferencia-se em relação à ideia escrita. A imagem dinamiza o processo de interação e induz a resposta rápida, tornando-se pouco provável que se possa analisar criticamente o que foi visto com base em aprendizados passados, como no caso da leitura (BOURDIEU, 1997 SANTOS J, 2004). A capacidade de adormecer a mente, mencionado por Postman $(2002)^{4}$, associa a televisão ao fenômeno da transmissão de ideias, sem que haja a necessidade de elaboração de conceitos, como ocorre na escrita e leitura que, para serem compreendidas, faz-se indispensável uma apreciação crítica e comparativa que desenvolva o raciocínio. A extinção desse procedimento extinguiria, nesse sentido, o desenvolvimento da mente.

\subsection{Os Media enquanto implicação da metamorfose cultural}

No que compete ao reposicionamento da criança enquanto classe, o acesso aos segredos antes resguardados pelos livros, são agora acessados de forma banal pelas crianças, sem gradação, sem censura ou pré-requisito de idade. Todos os assuntos são tratados pela televisão e redes sociais, tornando-se imprescindível criar-se constantemente novos temas, visto que estão no ar 24 horas por dia, 7 dias por semana, o que torna os temas repetitivos. Então, transforma-se em clichê o que outrora era tabu social, tratando de forma vulgar os mais diversos temas desde sexualidade a doenças mortais, Bourdieu (1997, p. 19), assevera:

\footnotetext{
[...] o acesso à televisão tem como contrapartida uma formidável censura, uma perda de autonomia ligada, entre outras coisas ao fato de que o assunto é imposto, de que as condições da comunicação são impostas e, sobretudo, de que a limitação do tempo impõe ao discurso restrições tais que é pouco provável que alguma coisa possa ser dita.
}

A exposição rotineira aos assuntos abordados pela televisão de forma superficial, devido ao caráter de urgência com que são divulgados os fatos, retira da criança (e até mesmo do adulto) a possibilidade de análise crítica e construção de ideias que só seria possível por intermédio de uma leitura analítica. A velocidade em que são dispostos os conteúdos midiáticos influencia também no conteúdo exibido e absorvido pelo público.

\footnotetext{
${ }^{4}$ Conceito desenvolvido por Rodolf Arnheim.

Ciência e Sustentabilidade - CeS | Juazeiro do Norte v. 2, n. 1, p. 56-81, jan/jun 2016
} 
Destaca-se ainda a busca do sensacionalismo transmitido pela televisão, em virtude da dramatização que exagera a realidade e cria o "efeito de real", produzido a partir das imagens que projetam a ideia de verdade sobre os fatos. Nesse contexto, os segredos são desmascarados não existindo a separação entre criança e adulto (BOURDIEU, 1997; FISCHER, 1996; MCLUHAN, 1974; MORIN, 2000; SANTOS J, 2004).

O papel dos meios comunicacionais funde-se com sua finalidade primeira, que é a de comunicar, sendo observável que, apesar dessa difícil remição, os meios comunicacionais devem ser compreendidos como simples médiuns que o são. Ao contrário do que McLuhan (1974) defendia, os meios comunicacionais são completamente desuníveis das mensagens que carregam. Santaella (2003, p. 25), complementa este entendimento:

Ora, mídias são meios, e meios, como o próprio nome diz, são simplesmente meios, isto é, suportes materiais, canais físicos, nos quais as linguagens se corporificam e através dos quais transitam. Por isso mesmo, o veículo, meio ou mídia de comunicação é o componente mais superficial, no sentido de ser aquele que primeiro aparece no processo comunicativo.

Esta imbricação de significâncias auxilia a compreensão de que os meios se modificam em torno do homem, com seu auxílio, e fundem-se nas formações culturais e comunicacionais, cumulando-se em torno de um todo reinventado. Todos os construtos anteriores serviram de sustentáculo para a recepção dos meios digitais, que forneceram um novo olhar sobre a recepção comunicacional, de modo a haver uma nova interação com o receptor (MCLUHAN, 1974; SANTAELLA, 2003).

À medida que a estruturação do cotidiano muda, temos, portanto, dentro do fenômeno da globalização, processos complexos de transformação da realidade, surgindo, como consequência, novas formas de identidades culturais em todo o mundo (GIDDENS, 2007; SERRA, 2004).

\subsection{Identidade em construção: a marca e o monstro}

Os modelos míticos funcionam como uma base de parâmetros que são designados como padrão, que servem de guias àqueles que querem seguir os moldes sociais. Entretanto, os novos mitos distribuem-se nas imagens televisivas, 
que expõem um novo padrão a cada estação, cria-se a busca pela pureza inalcançável de que trata Bauman (1998), cada nova interação ressurge com novos mitos que trazem consigo a promessa da realização pelo consumo.

É dado a estes indivíduos o poder de escolha, que logo torna-se uma obrigação, dentro da ótica de aceitação social (MORAN, 2000). Rocha e Rodrigues (2013, p. 36), ressaltam: "o corpo é obrigado a se manifestar", a criança e o jovem confundem-se em suas delineações, e há, portanto, um forte apelo ao desenvolvimento físico e social desses indivíduos, inserindo-os numa situação de pressão ao desenvolvimento precoce.

A motivação induz, mas não determina o consumo. O relacionamento com os símbolos e seu empoderamento, capaz de modificar o cotidiano, é responsável por ditar os padrões, que podem ou não ser a escolha do consumidor que, por sua vez, possui diferentes experiências que auxiliam na tomada de decisão (GIGLIO, 2013; SOLOMON, 2011).

O consumidor infantil, no entanto, encontra-se em processo de desenvolvimento intelectual e psicológico, interagindo com o meio social em busca de determinar padrões básicos de comportamento. Assim como observa Vygotsky (2007), o desenvolvimento sofre implicações das práticas de consumo, mais especificamente do processo imaginativo desencadeado pela publicidade quimérica, gerando o consumo adoecido: o consumismo. A mediação de instituições que atuam e intermediam as mídias direcionadas ao público infantil, visam garantir o desenvolvimento desses indivíduos, de forma integral, em sua completude e intelectualidade (MCNEAL ET AL, 2000; FISCHER, 1996).

Campbell (2006) confere ao consumo o poder de definição do indivíduo que o pratica. Isto é, as escolhas pressupõem ao consumidor sua identidade social, ao mesmo tempo em que ele interage com os estímulos da mídia de massa. O autor conclui: "Somos definidos por nossos desejos, ou por nossas preferências " (CAMPBELL, 2006, P. 51). As possibilidades inúmeras existentes no mercado permitem um diálogo entre o consumidor, seus desejos e outros conhecimentos. Considerar o consumo um meio de reconhecer-se enquanto indivíduo ressalta ainda mais a natureza intimista do ato de comprar, não sendo apenas uma simples decisão, mas sim um processo dinâmico capaz de identificar a possibilidade de concretização dos desejos. 
O consumo transcende o simples ato de ter, a busca por significados impregnados nos objetos é inata ao ser humano. Esta procura correlaciona comunicação, sentido, símbolo e experiência, atribuindo às diversas esferas valores distintos. A esse respeito, Capra (2008, p. 31), salienta: "significado é a experiência de um contexto, e contexto é um padrão de relações entre objeto ou evento que está sendo estudado e seu ambiente".

O quadro que se forma é o da conectividade sinérgica, Tubella (2000, p. 28) salienta: "se entendermos o conceito de identidade não como uma dada realidade, mas como um processo em progressão, conseguimos apreciar o importante papel da comunicação no cimentar daquele processo". Deve-se observar que os processos comunicacionais impactam diretamente na construção da subjetividade e, consequentemente, nas escolhas de consumo. Como há comunicação há também a transformação do "eu".

Destarte, todo esse processo de construção do "eu" por meio da comunicação, dá-se através da cognição. Capra (2002, p. 41) ${ }^{5}$ a designa como o processo da própria vida, uma vez que o indivíduo está completamente em aprendizado, e completa ainda: "[...] a cognição envolve todo o processo da vida inclusive a percepção, as emoções e o comportamento".

Dentro disso, a cognição se liga a autopoiese, que diz respeito às modificações das estruturas, de modo contínuo, mantendo seu padrão de organização em teias. Em outros termos, segundo essa teoria, o ser vivo conecta-se ao ambiente por meio das interações correntes que modificam as estruturas dentro do sistema. Entretanto, o ambiente não determina tais mudanças, apenas a incita. Esta teoria diz respeito ao aprendizado e contínuo desenvolvimento do indivíduo, isto é, registra o comportamento em dado ponto de modificação estrutural, que poderá ser acessado num instante futuro (CAPRA, 2002; MATURANA,2002, 2001, 1995; MORAES, 2002).

Assim, quando houver, no ambiente, uma perturbação que implique numa mudança, o sistema estrutural reage modificando-se. Entretanto, é o próprio ser que decide o que aceitar como perturbação ao ambiente, que desencadeia a mudança. Capra (2002, p. 43) completa: "As interações do sistema vivo com seu ambiente são interações cognitivas, e o próprio processo do viver é o processo de cognição ". 
Tendo em vista a compreensão dos constructos indenitários, destacam-se os afluxos informacionais, que determinam as perturbações dos sistemas sociais, os quais produzem significados comutativos que se refletem nos valores, crenças e símbolos (MATURANA; VARELA, 1980; MORAES, 2002). Os processos de comunicação estão enlaçados ao ato de comprar, seja por peças publicitárias, mensagens verbais, escritas ou imagens.

Desse modo temos o desenvolvimento dos mitos endossantes das marcas que os promovem e se validam comutativamente. A marca delimita fronteiras entre os grupos sociais, demonstra todo seu poder de persuasão e significância. Camilo (2004, p. 182) define marca da seguinte forma:

Concebemos por marca um enunciado de individualização, se quisermos um enunciado de singularização, de demarcação de uma determinada realidade. A marca é o enunciado de uma segmentarização, do estabelecimento de uma fronteira, de uma determinação de conjuntos.

As marcas representam, no inconsciente do consumidor, algo além do âmbito econômico, atingindo valores expectados e desejados por esses, como por exemplo: status, segurança, seriedade, etc. É isso que Camilo (2004) defende a ideia de a marca representar, no imaginário dos indivíduos, a representatividade do monstro, que em seu cerne elabora-se do fantástico e quimérico, inatingível em sua elaboração. A fascinação pelo irreal, que se elabora na representatividade da marca, é a mesma que a do mito, ambos atraem por aquilo que não se compreende a miúde. Todavia, não se deve confundir o caráter monstruoso com a qualidade que a marca perpetua, do contrário a marca acabar-se-ia desfalecendo em sua dimensão perceptiva em relação aos silogismos que atrai. A este respeito, Camilo (2004, p. 192) conclui:

\footnotetext{
Existe, portanto, um ponto de comum entre o monstro e a marca: ambas as categorias fascinam - impressionam e prendem a atenção pelo facto de simplesmente existirem. Por fascínio entendemos o sentimento de total atracção por qualquer coisa. Trata-se de uma sensação que implica sempre a perda da liberdade em relação à coisa que fascina.
}

Implicam aqui observações a respeito do processo de formulação das marcas e compreende-se, com isso, que há distinção entre o fascínio que se relaciona com 
o monstro e o que se relaciona com a marca. Enquanto o fascino do monstro produz um efeito de grotesco, a marca promove o fascínio glorioso (CAMILO, 2004).

\section{CONSUMO E VULNERABILIDADE: UMA QUESTÃO AMBIENTAL}

Deve-se compreender infância em sua acepção história, cultural, social, psicológica e particularmente legal, isso porque o Brasil compõe o rol dos países que regulamentam a publicidade voltada para crianças e adolescentes. O objetivo da adoção de parâmetros legais visa assegurar o desenvolvimento sócio educativo da infância exposta à publicidade infantil e abusiva. Conforme o Estatuto da Criança e do Adolescente (ECA), no Art. $2^{\circ}$, estabelece que para os efeitos da lei considerarse-á criança a pessoa até 12 anos de idade incompletos e em adjunto da Resolução 163/2014 do Conselho Nacional dos Direitos da Criança e do Adolescente (Conanda), que considera abusivo o direcionamento da publicidade e da comunicação mercadológica à criança e ao adolescente.

A integralidade do texto dirige-se ainda à publicidade e comunicação mercadológica, que pode ser encontrada nos interiores de creches e escolas assim como na composição dos uniformes e materiais escolares das mesmas. O Instituto Alana destaca-se no combate a qualquer tipo de comunicação mercadológica e dedica-se a ações voltadas a esse fim, assim como a Agência de Notícias dos Direitos da Infância (ANDI), organização da sociedade civil, que age como influente articuladora de ações em mídia para o desenvolvimento. Entretanto, prolongam-se os debates sobre a regulamentação estatal e uma possível censura à comunicação, que remete ao sistema ditatorial de outrora.

Compreende-se que um setor, como é o caso da comunicação, dotado de poder de informação e influência sobre a população, em particular a infantil, deveria submeter-se a um sistema regulador, como Bourdieu (1997) ressalta que muitas redes de televisão são proprietárias de grandes oligopólios e tornam-se imunizadas, tendo em vista que o estado isentar-se-ia de restringi-las no âmbito comunicacional, temendo retaliações. Tal fato, poderia converter-se na atual situação em que, apesar de não serem detentoras de oligopólios, as grandes emissoras brasileiras possuem o monopólio da influência difusora de informações, o autor completa: " A televisão 
tem uma espécie de monopólio de fato sobre a formação das cabeças de uma parcela muito importante da população" (BOURDIEU 1997, p. 23).

A cultura do consumo prega o apego à coisa material, ao ponto de implicar na percepção de mundo dos pequenos consumidores. Quando não é possível satisfazer às necessidades de compra, as tensões extrapolam o interno e impactam no convívio social. O impacto real da impossibilidade de consumir impede os sujeitos de identificarem-se com seus produtos e, consequentemente, com o grupo social a que pertencem (CAMPOS, 2003).

A função de amenizar as diferenças individuais, que é possível graças ao sistema de consumo e da publicidade comunicacional, que põe modelos de identificação prepostos, direciona os sujeitos a uma anulação das diferenças por meio da produção preestabelecida de conteúdo. Quando não se enquadra nesses moldes, o indivíduo é distanciado do seu propósito de identificação com a marca ou produto, isto é, o consumo concretiza toda a crença que se forma em torno da possibilidade de compra e consequente efetivação de uma subjetividade (BAUDRILLARD, 1967; CAMPOS, 2003).

O quadro que se forma é o do adoecimento do consumidor infantil por meio da imersão deste em esferas do conhecimento trabalhadas pela Cultura das Mídias, no intuito de manipular o desejo ascendente de conhecer a si por meio do ato de adquirir novos bens, ou seja, o consumo proporciona o reconhecimento e identificação dos indivíduos, não simplesmente pelo produto adquirido, e sim pela experienciação do fato e sua interação interpessoal com os sujeitos envolvidos. As consequências ambientais implicam em excessos de resíduos advindos da incessante busca do encontrar-se que não se concretiza, apenas, por meio da aquisição material de bens, os quais são divulgados pela mídia de massa como solução para os problemas emocionais adquiridos pelo hedonismo exacerbado e a obrigatoriedade de escolha (BUCHT; FEILITZEN, 2002; ROCHA; RODRIGUES, 2013).

É inegável o desenvolvimento atingido pela sociedade de consumo. O alcance das informações, as comodidades e os avanços tecnológicos elevam o homem a patamares de conforto nunca antes atingidos. Entretanto, o caminho que se trilha é o do consumismo exacerbado, que degrada o meio ambiente através da poluição, desmatamento e consequente desigualdades sociais. Faz-se imperioso 
gerar a empatia dos jovens e adolescentes, tendo em vista a percepção mais apurada do ambiente externo e seus agentes influenciadores da mudança (MOTTA, 1998)

Conforme a Lei n 9.795 (BRASIL, 1999, art. 2), a educação ambiental deve estar presente em todos os âmbitos da educação. Segue na mesma Lei, em seu artigo terceiro, a atribuição às instituições educativas a promoção da educação ambiental, compreendendo a conservação, recuperação e melhoria do meio ambiente, visando incutir nos educandos uma percepção mais abrangente da necessidade de mitigar atitudes, a fim de se atingir um equilíbrio ambiental.

Para Cuba (2010), a educação formal é essencial no alicerce da fundamentação dos valores relacionados à sustentabilidade, tendo em vista que o aluno, através dela, percebe-se como membro integrante da sociedade. É factível que as ações humanas, em descompasso, estão diretamente relacionadas com os desequilíbrios ecológicos, ocasionados principalmente pela conduta consumista que perpetua os excessos à custa da natureza, o autor segue ainda enfatizando a importância da educação ambiental (CUBA, 2010, p. 26):

\begin{abstract}
Assim, a educação ambiental deve ser acima de tudo um ato político voltado para a transformação social, capaz de transformar valores e atitudes, construindo novos hábitos e conhecimentos, defendendo uma nova ética, que sensibiliza e conscientiza na formação da relação integrada do ser humano, da sociedade e da natureza, aspirando ao equilíbrio local e global, como forma de melhorar a qualidade de todos os níveis de vida.
\end{abstract}

Para Boff (1999), faz-se imperativo a modificação dos hábitos em busca do desenvolvimento alinhado com as demandas ambientais e seus limites, não significando, para tanto, um retrocesso dos padrões, mas, uma mitigação dos parâmetros consumidores, buscando um consumo sustentável. É possível identificar nos Parâmetros curriculares nacionais para o Ensino Médio (BRASIL, 1997), a asseveração de que não seria possível, pela composição convencional das grades curriculares, assegurarem o desenvolvimento dos alunos enquanto participantes sociais efetivos, fazendo-se imprescindível a interação sociocultural dos agentes educadores em diferentes esferas da educação (BUCHT; FEILITZEN, 2002).

O Programa Nacional de Educação Ambiental (PRONEA) (BRASIL, 2005), estende estas compreensões de educação ambiental, levando em conta os aspectos múltiplos contidos no Brasil, sejam eles culturais, naturais ou históricos, devendo 
esses se integrarem a fim de que se modifique a realidade dos desejos materiais em sua construção simbólica e nos padrões de consumo. Mudar atitudes individuais em busca da melhoria global é o foco da educação ambiental. Em A Carta da Terra (1992), a necessidade de uma visão compartilhada é exaltada para que se alcancem critérios aceitáveis de preservação.

\section{MATERIAIS E MÉTODOS}

Visando atingir as predições sugeridas, foi utilizada pesquisa quantitativa exploratória, buscando a validação das hipóteses propostas, mediante a utilização de dados estruturados. A análise dos resultados obtidos deu-se por meio da estatística descritiva, Reis (1996 P. 15) em relação a seus aspectos define: "Consiste na recolha, apresentação, análise e interpretação de dados numéricos através da criação de instrumentos adequados: gráficos e indicadores numéricos". A construção de um questionário misto deu-se almejando atingir os objetivos de maior compreensão dos fenômenos estudados. As perguntas, em sua maioria, foram compostas por questões fechadas e dicotômicas compondo ainda respostas discursivas e de escolha múltipla (ZANELLA, 2009).

Conforme Almeida e Freire (2003), população é o apanhado de indivíduos que são retirados do universo, viabilizando o estudo dos fenômenos correntes realizado pelo pesquisador. Deve-se ainda levar em consideração que em pesquisas quantitativas não se considera, necessariamente, um vínculo numérico especifico para se qualificar a representatividade da pesquisa, uma vez que os indivíduos, dentro da amostra elencada devem abranger as múltiplas dimensões em relação ao problema investigado (MINAYO, 2013)

A população escolhida foi, de acordo com o Instituto Nacional de Estudos e Pesquisas Educacionais (INEP, 2014), de 15.661 mil pessoas, que se referem a quantidade de alunos devidamente matriculados em instituições de ensino, sejam públicas ou privadas, do ensino médio e fundamental, da $5^{\text {a }}$ a $8^{\text {a }}$ série e anos finais. Estratificando, desse modo, a população pesquisada, a fim de se apurar a delineação da pesquisa (CRESWELL, 2007). O erro amostral aderido foi de 7\% com nível de confiança em 95\%, gerando, de acordo com o cálculo, uma amostra de 194 alunos, dando-se pela seguinte fórmula (SANTOS G., 2015): 
Onde:

$\mathrm{n}$ - amostra calculada

$\mathrm{N}$

Z associada

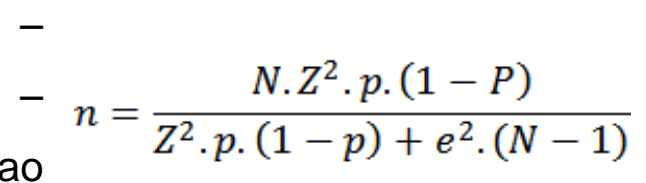

População

Variável normal padronizada

$p$ - verdadeira probabilidade do evento

e - erro amostral

Dentre os diversos métodos, optou-se pelo questionário, pois, sua aplicação demanda menos tempo dos alunos, otimizando, portanto, todo processo sem prejuízo para nemuma das partes ${ }^{6}$ (LAKATOS; MARCONI, 2003). O pré-teste realizou-se com $10 \%$ da amostra encontrada, tendo em vista a fidedignidade e eficácia do questionário. Outros temas foram abordados a fim de se alcançar a proposta inicial, sendo possível identificar tal necessidade por meio do pré-teste, tornando-o válido e operante o qual Lakatos e Marconi (2003), se referem.

O tipo de amostragem, em virtude da escolha da aplicação do questionário, foi por conveniência, que se utiliza de indivíduos, dentro da população predeterminada, disponíveis da população acessível (LUNA Foo, 1998). Oliveira (2001, p. 5), esclarece a esse respeito, referindo-se ao emprego de tal amostragem: "[...]esse procedimento consiste em simplesmente contatar unidades convenientes da amostragem, é possível recrutar respondentes tais como estudantes em sala de aula[...]".

Visando maior relevância e comprometimento, o colhimento dos dados realizou-se somente após a assinatura do Termo de Consentimento Livre e Esclarecido (TCLE), efetivada pelos pais dos menores em questão. O questionário proposto foi composto por 18 questões e garantiu-se o sigilo das informações obtidas. A pesquisa foi realizada durante os dias 22 e 23 de junho, em três instituições de ensino sendo duas Públicas Estaduais e uma particular. Foi utilizada

\footnotetext{
${ }^{6}$ Uma vez que a coleta ocorreu in loco
}

Ciência e Sustentabilidade - CeS | Juazeiro do Norte v. 2, n. 1, p. 56-81, jan/jun 2016 
a estatística descritiva como método de análise dos resultados obtidos por meio de um questionário a um grupo especifico visando compreender aspectos específicos de seu comportamento em relação ao consumo (PRODANOV; FREITAS, 2013).

\section{RESULTADOS E DISCUSSÃO}

A partir dos dados coletados, foi possível identificar que a maioria dos indivíduos questionados era do sexo feminino, com idades variando entre 11 e 17 anos, o que possibilita uma maior compreensão e associação com os tópicos sugeridos. Visto que foram elaborados em formato de questionário, com questões múltiplas escolhas, se assemelhando às estruturas em que são elaborados os materiais didáticos das escolas referidas.

Tabela1 - Quantidade de indivíduos por gênero.

\begin{tabular}{c|c|c}
\hline Gênero & Quantidade & Frequência de idade \\
\hline Feminino & 114 & $11-16$ \\
Masculino & 80 & $13-17$ \\
Total & 194 & $11-17$ \\
\hline
\end{tabular}

Fonte: Pesquisa direta, 2015.

Por meio da proposição apresentada na Tabela 2, foi possível identificar a relação existente entre a mídia e a realização de compras, tecendo um quadro da influência da mídia de massa no processo de incentivo ao consumismo, ou compra por impulso.

Tabela 2 - Influência da mídia nas compras e arrependimento por adquirir produtos.

\begin{tabular}{c|c|c|c}
\hline \multirow{2}{*}{ Mídia influência nas compras } & \multicolumn{3}{c}{$\begin{array}{c}\text { Arrependimento por comprar influenciado pela } \\
\text { mídia }\end{array}$} \\
\cline { 3 - 4 } & & Sim & Não \\
\hline Sim & 147 & 72 & 75 \\
Não & 47 & 13 & 34 \\
Total & 194 & 85 & 109 \\
\hline
\end{tabular}

Fonte: Pesquisa direta, 2015.

Outro ponto acerca da influência na construção de uma cultura de consumo em crianças e jovens, é a intervenção de outros agentes na escolha dos bens consumidos. Por meio da Tabela 3, foi possível averiguar se os pais possuem, em algum nível, o poder de influenciação nas compras dos jovens consumidores. 


\begin{tabular}{c|c}
\hline Respostas & Frequência de respostas \\
\hline Eu compro o que tenho vontade & 84 \\
Meus pais escolhem comigo & 110 \\
Total & 194 \\
\hline
\end{tabular}

Fonte: Pesquisa direta, 2015.

As atividades realizadas fora da escola interferem na construção da cultura infantojuvenil, uma vez que elaboram constructos de percepção social na formulação de grupos de interação. Desse modo, mediram-se, por meio da questão apresentada no Gráfico 1, quais os padrões de interação dos pesquisados no tempo livre com as mídias de massa e cultura das mídias.

Gráfico 1. Qual atividade realiza no tempo livre?

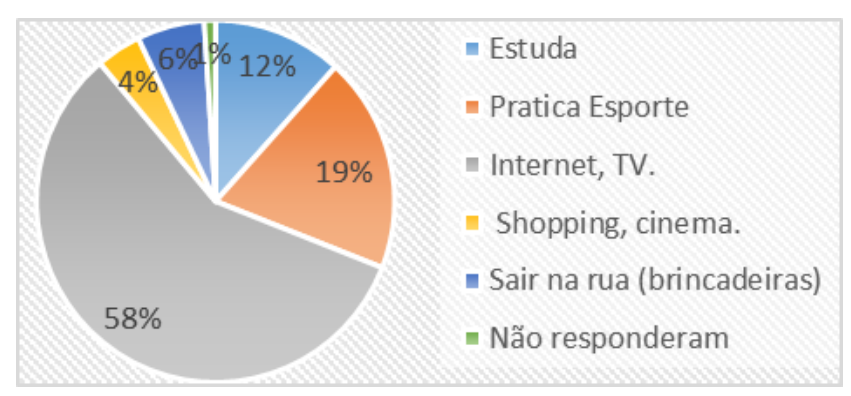

Fonte: Pesquisa direta, 2015.

Ainda com o objetivo de perceber a interatividade entre os questionados e os aparelhos eletrônicos, que permitem conexão com a internet, levantou-se o tema de compra em aplicativos de dispositivos móveis. Durante a aplicação dessa questão foi explicado para aqueles alunos que tivessem dúvida relacionada a esse tipo de compra. É possível verificar o resultado obtido pelo Gráfico 2:

Gráfico 2. Já realizou compras em aplicativos de dispositivos móveis?

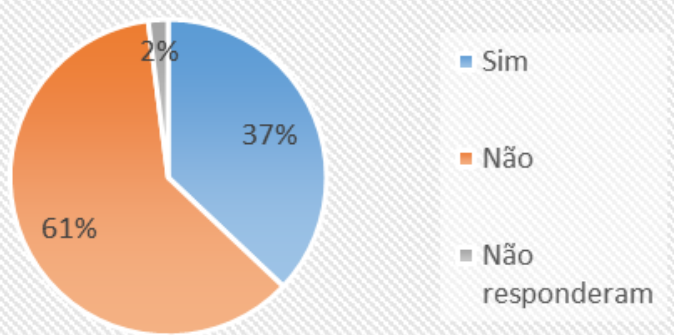

n. 1 , p. 56-81, jan/jun 2016 
Visando traçar um paralelo entre o tempo gasto fora da escola e o uso de mídias conectadas à internet, foi elaborada a questão abordada na Tabela 4, sendo, então, possível identificar qual das duas atividades ocupa mais tempo dos jovens consumidores.

Tabela 4 - Horas de estudo diário em relação as horas de conexão.

\begin{tabular}{c|c|c|c}
\hline Respostas & Quantidade & $\begin{array}{c}\text { Média de horas de } \\
\text { estudo h/dia }\end{array}$ & $\begin{array}{c}\text { Média de horas de } \\
\text { conexão h/dia }\end{array}$ \\
\hline Sim & 119 & 1 & 3,31 \\
Não & 75 & 0 & \\
Total & 194 & 194 & \\
\hline
\end{tabular}

Fonte: Pesquisa direta, 2015

Há ainda a interação da cultura com o corpo, o qual reflete os signos escolhidos pelo indivíduo para se identificar junto aos grupos de referência. Para se analisar esta premissa os questionados foram expostos à pergunta da Tabela 5.

Tabela 5 - Você se sente satisfeita (o) com seu corpo?

\begin{tabular}{|c|c|c|c|}
\hline Respostas & Feminino & Masculino & Geral \\
\hline Não, gostaria de mudar. & 44 & 21 & 65 \\
\hline Sim, estou satisfeito. & 54 & 50 & 104 \\
\hline $\begin{array}{l}\text { Não estou satisfeito, } \\
\text { mas não mudaria. }\end{array}$ & 16 & 9 & 25 \\
\hline Total & 114 & 80 & 194 \\
\hline
\end{tabular}

Fonte: Pesquisa direta, 2015.

Os ídolos que percorrem o imaginário infantojuvenil semeados pela mídia constituem outro fator preponderante na relação com a cultura corrente. Identificar a existência desses personagens entre os questionados foi determinante para traçar as intermediações entre mídia, cultura e consumo, conforme retratado no Gráfico 3. 
Gráfico 3. Existe algum personagem que você admira?

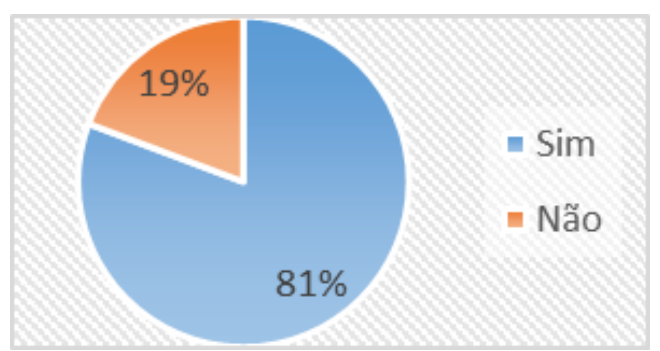

Fonte: Pesquisa direta, 2015.

A exposição dos jovens à mídia produz, em suas percepções de cultura, efeitos distintos, de acordo com o conteúdo exibido. Em busca de entender os encadeamentos consequentes desta experiência, buscou-se elencar os principais programas vistos pelos pesquisados e se os pais controlavam o que esses jovens assistiam. Segue a Tabela 6 com as respostas obtidas:

Tabela 6 - Principais programas vistos e controle parental em relação ao conteúdo visto.

\begin{tabular}{c|c|c|c}
\hline \multirow{2}{*}{ Respostas } & \multirow{2}{*}{ Frequência } & Seus pais controlam o que você assiste \\
\cline { 2 - 4 } Novelas & 51 & 26 & Não \\
Reality show & 5 & 2 & 25 \\
Esportes & 38 & 11 & 3 \\
Documentários & 4 & 2 & 27 \\
Séries & 57 & 25 & 2 \\
Desenhos animados & 23 & 5 & 32 \\
Outros & 16 & 4 & 18 \\
Total geral & 194 & 75 & 12 \\
\hline
\end{tabular}

Fonte: Pesquisa direta, 2015.

As roupas representam signos culturais tangíveis e de elevada interação no cotidiano, definindo e representando muito da personalidade das crianças e dos adolescentes em relação aos grupos de referência. Por esse motivo, identificou-se quais agentes influíam no processo de compra das mesmas, observa-se essa premissa por meio do Gráfico 4:

Gráfico 4. Quem escolhe suas roupas?

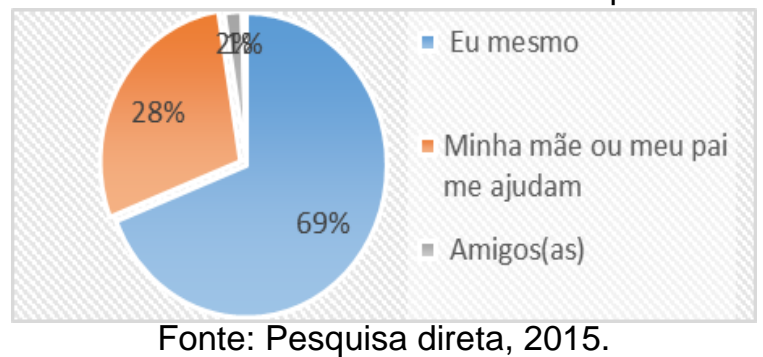

Ciência e Sustentabilidade - CeS | Juazeiro do Norte v. 2, n. 1, p. 56-81, jan/jun 2016 
A mídia veicula, em menor escala, promoções ao bem comum e ajudas humanitárias, muitas vezes compelida pelo estado e outrora espontaneamente. Entretanto, $83 \%$ dos participantes afirmaram nunca ter participado de nem um tipo de campanha que visa o bem comum, demostrando, desse modo que nos encontramos diante de um crescimento tecnológico em simbiose com a miséria, de forma que, para se ter uma vida sustentável, deve-se adaptar a tecnologia e a ecologia humana, gerando a responsabilidade pessoal em benefício do todo (GADOTTI, 2008).

Gráfico 5. Participa de campanhas promovidas pela mídia visando o bem comum?

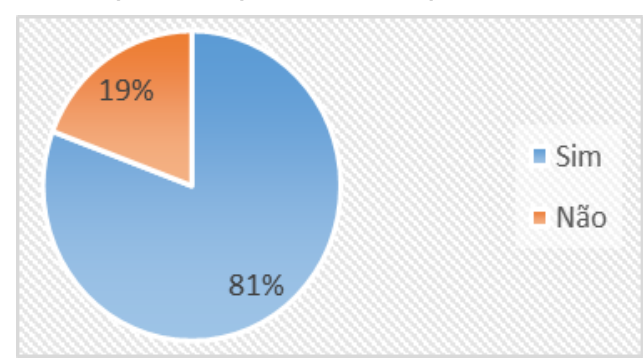

Fonte: Pesquisa direta, 2015.

Os entrevistados foram aferidos ainda em relação a seu interesse pelo meio ambiente, $43 \%$ afirmaram interessar-se muito pelo meio ambiente enquanto $15 \%$ responderam que teriam pouco ou nenhum interesse pelo meio ambiente. Entretanto, na pergunta seguinte, verificou-se que $53 \%$ dos questionados escolhiam a qualidade como determinante na compra de determinados produtos, desconsiderando os aspectos ambientais. $50 \%$ dos entrevistados afirmaram raramente ou nunca ter acesso, durante as aulas, a assuntos relacionados com meio ambiente, demostrando a carência em se tratar das questões ambientais em sala de aula.

Gráfico 6. Qual seu interesse pelo meio ambiente?

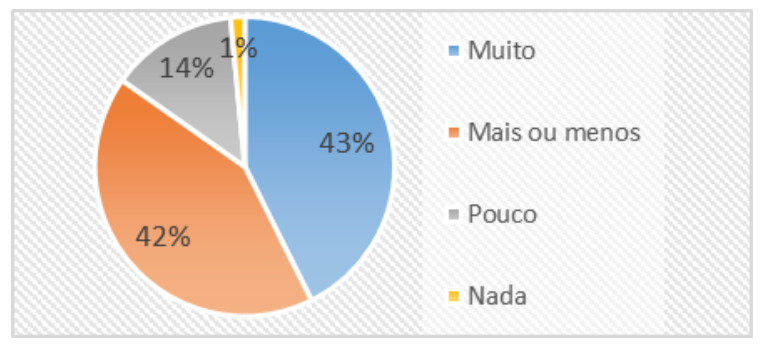

Fonte: Pesquisa direta, 2015. 
Gráfico 7. Com qual frequência são tratados os assuntos relacionados com meio ambiente?

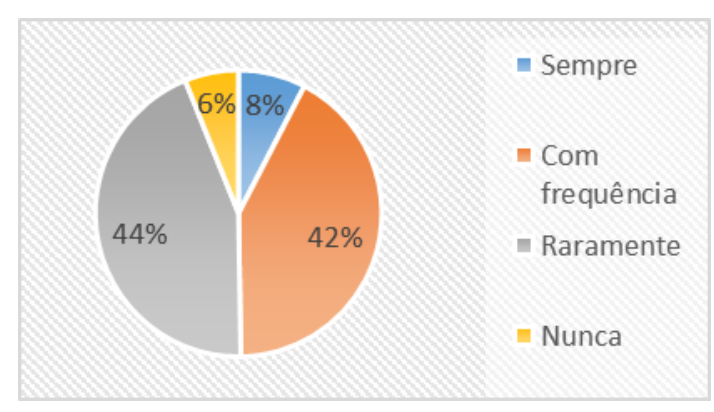

Fonte: Pesquisa direta, 2015.

Gráfico 8. Aspecto mais levado em conta para efetivação da compra.

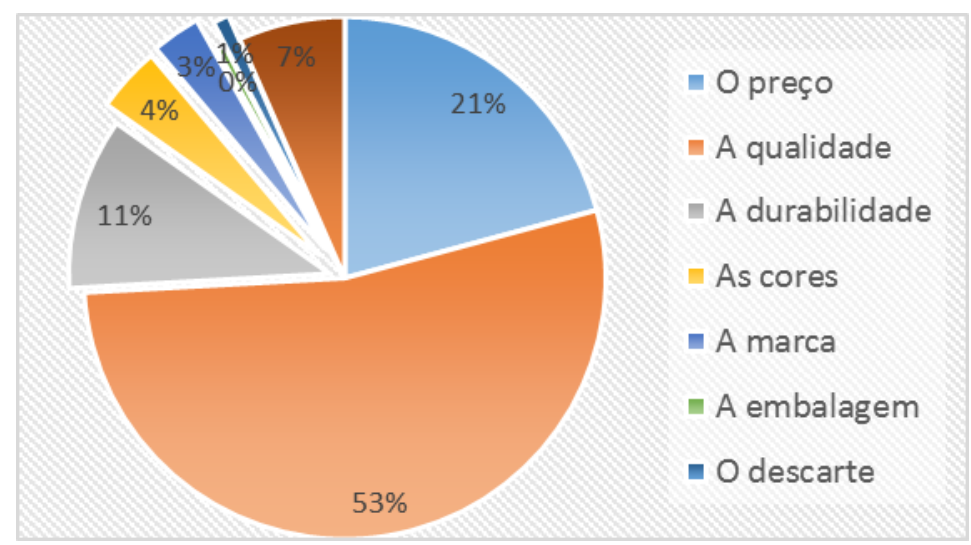

Fonte: Pesquisa direta, 2015.

Os dados colhidos demostram o reflexo da dissociação corrente entre educação ambiental e educação formal. Apesar da educação ambiental ser reconhecida como disciplina de ensino obrigatório em instituições de educação, sejam privadas ou públicas, é um tema pouco abordado em sala de aula. Deste modo, os jovens, que deveriam ser formados como cidadãos participantes e influentes, permanecem expostos a maior parte do tempo às mídias de massa que são responsáveis por distorcer a realidade (MORIN, 2000; CUBA, 2010). 


\section{CONCLUSÕES}

Os resultados obtidos, através da coleta e análise dos dados, demonstram que realmente existe o encantamento por parte dos jovens consumidores em relação aos seus ídolos e que, desse modo, a mídia impacta diretamente na decisão de compra, levando-os ao consumismo e com isso interferindo no que se refere ao panorama que se encontra o meio ambiente, que é sacrificado em nome da evolução consumista, atingindo, dessa maneira, os objetivos gerais propostos.

A escola, mesmo havendo o comprometimento legal, não interfere de forma positiva nas relações dos educandos com o sistema de indução ao consumo, fica claro que há uma demanda de ensino para o consumo sustentável, fato que confirma a concretização dos objetivos específicos. Diante deste cenário, há apenas uma forma de combatê-la: por meio da educação para o consumo em benefício do meio ambiente.

Em vista dos argumentos aludidos e dos dados coletados, é cogente o fato de a mídia interferir diretamente no consumo infantil e consequentemente na construção da cultura, tendo em vista seu aspecto comunicacional cognitivo e construtivo. É por meio do consumo que o sujeito transfere e recebe os significados impregnados no objeto consumido, interagindo e repassando para os integrantes do grupo novas impressões e leituras a respeito desses signos, completando um ciclo que se abre constantemente, reiterando, modificando e construindo o indivíduo.

Este trabalho reforça a percepção destas relações e demonstra a interferência da Cultura de Massa e da Cultura das Mídias na construção da subjetividade cultural em crianças e adolescentes, servindo de alicerce para novas investigações sobre o tema e abrindo novas sendas de debate sobre o assunto proposto. Para se abranger a compreensão das relações entre consumo e juventude, faz-se necessário observar outros aspectos, como educação do consumidor infantojuvenil e sua vulnerabilidade para o consumo, sendo esta uma nova abordagem a respeito do tema. 


\title{
CHILDREN AND SUSTAINABLE CONSUMPTION: AN APPROACH THE MEDIA CONSTRUCTION OF SUBJECTIVITY IN THE ENVIRONMENTAL CONTEXT
}

\begin{abstract}
Changes in organizational standards that aim for environmental certification policies increasingly rigid, in order to preserve the environment, forget education for consumption. The expansion of consumption reaches higher levels each year, making it impossible to unlink the practice of youth everyday consumption. However one must understand the practice of consuming not as harmful, but passive adaptation to the current scenario of scarcity of primary resources. We sought to understand how the media impacts of Culture in the relevant decisions to consumer goods and services related to public infantojuvenil and the perception of these individuals regarding the implications for the environment. It is in this context that presents the general objective of this research: to determine the influence of the media and the formal school building the child consumer and their environmental awareness. Therefore it employed an exploratory and descriptive method with quantitative design from the application of a mixed questionnaire with 194 students from public and private schools. It is pointed out as the main result of the fact that the school becomes a fundamental tool in the education of consumers who are immersed in illusory webs woven by advertising and reinforced by social groups and their symbols. The clarification and guidance that young people should take place within the school, which needs to develop in students a holistic view of individuals and the environment they live in, with the possible formation of conscience and recommended actions in the evaluation of critical actions for sustainability environmental.
\end{abstract}

Keywords: Culture. Communication. Consumption. Subjectivity. Youthful

\section{REFERÊNCIAS}

BAUDRILLARD, J. MacLuhan, M. Understanding Media: the Extensions of Man, Mc Graw-Hill Book company, cop. 1964. L'Homme et la société, v. 5, n. 1, p. 227-230, 1967.

BAUMAN, Z. O mal-estar na pós-modernidade. Rio de Janeiro: Jorge Zahar ed, 1998.

BOFF, L. Saber Cuidar. Ética do Humano: compaixão pela Terra. Petrópolis, Ed. Vozes, 1999.

BOURDIEU, P. Sobre a televisão. Rio de Janeiro Jorge: Jorge Zahar , 1997.

BRASIL. Lei no 9.795, de 27 de abril de 1999. Dispõe sobre a Educação Ambiental, institui a Política Nacional de Educação Ambiental e dá outras providências. Diário Oficial [da] República Federativa do Brasil, Brasília, DF, v. 137, n. 79, 8 abril 1999. Seção 1, p. 1-3 
. Ministério da Educação. Secretaria de Educação Média e Tecnológica.

Parâmetros curriculares nacionais para o ensino médio. Brasília: MEC/SEMTEC, 1997. Versão preliminar.

. Ministério do Meio Ambiente. Diretoria de Educação Ambiental; Ministério da Educação e Cultura. Coordenação Geral de Educação Ambiental. Programa Nacional de Educação Ambiental: ProNEA. 3. ed. Brasília, DF, 2005.

. Ministério do Meio Ambiente. Agenda 21; Organização das Nações Unidas.

Carta da Terra. Brasília: Senado Federal, Subsecretaria de Edições Técnicas, 2002. Disponível em:

$<$ http://www.mma.gov.br/estruturas/agenda21/_arquivos/carta_terra.pdf> Acesso em: 30 junho. 2015.

BUCHT, C., \& FEILITZEN, C. V. Perspectivas sobre a criança e a mídia. Brasília: UNESCO, SEDH/ Ministério da Justiça, 2002.

CAMILO, E. J. M. Monstruosidade das marcas: da massificação à absoluta singularidade. In: SANTOS, José Manuel. Teorias da comunicação. Universidade da Beira Interior, 2004.

CAMPBELL, C. Eu compro, logo sei que existo: as bases metafísicas do consumo moderno. In BARBOSA, Lívia; CAMPBELL, C. (Org.). Cultura, consumo e identidade. Rio de Janeiro: Ed. FGV, 2006.

CAMPOS, C. C. G. de; SOUZA, S. J. e. Mídia, cultura do consumo e constituição da subjetividade na infância. Psicol. cienc. prof., Brasília, v. 23, n. 1, p. 12-21, Mar. 2003. Disponível em:

$<$ http://www.scielo.br/scielo.php?script=sci_arttext\&pid=S1414-

$98932003000100003 \&$ Ing=en\&nrm=iso $>$. access on 02 Nov. 2015.

http://dx.doi.org/10.1590/S1414-98932003000100003 .

CAPRA, F. As conexões ocultas. São Paulo. Cultrix, 2002.

CUBA, M. A. Educação ambiental na escolas. ECCOM, Lorena, v. 1, n. 2, p. 23-31, jul./dez. 2010. Disponível em:

<http://publicacoes.fatea.br/index.php/eccom/article/viewFile/403/259> Acesso em: 30 jun. 2015 
FISCHER, R. M. B. Adolescência em discurso: mídia e produção de subjetividade. Tese de Doutorado. Universidade Federal do Rio Grande do Sul. Porto Alegre, 1996.

GIDDENS, A. Mundo em descontrole. $6^{\circ}$ ed. Rio de janeiro: Record, 2007.

GIGLIO, E. M. O comportamento do consumidor.4 Ed. São Paulo: Cengage Learning, 2013.

GIL, A. C. Como classificar as pesquisas. Como elaborar projetos de pesquisa, v. 4, p. 41-56, 2002.

INSTITUTO NACIONAL DE ESTUDOS E PESQUISAS EDUCACIONAIS ANÍSIO TEIXEIRA. Banco de Dados. Disponível em: http://www. inep .gov .br Acesso em: 16 jun. 2015.

LAKATOS, E. M; MARCONI, M. de A. Fundamentos da metodologia científica. $5^{\circ}$ Ed. Sãp Paulo: Altas, 2003.

LIMA, T. C. S; MIOTO, R. C. T. Procedimentos metodológicos na construção do conhecimento científico: a pesquisa bibliográfica. Revista Katálysis, v. 10, n. 1, p. 37-45, 2007.

LINN, S. Commercializing childhood: The corporate takeover of kids' lives. Multinational Monitor, v. 30, n. 1, p. 32-38, 2008.

LUNA Fon, B. Seqüência básica na elaboração de protocolos de pesquisa. Arq. Bras. Cardiol, São Paulo, v. 71, n. 6, p. 735-740, Dec. 1998 . Disponivel em $<$ http://www.scielo.br/scielo.php?script=sci_arttext\&pid=S0066782X1998001200001\&lng=en\&nrm=iso >. access on 13 Oct. 2015. http://dx.doi.org/10.1590/S0066-782X1998001200001.

MORIN, E. Cultura de massas no século XX- neurose. $9^{\circ}$ Ed. Rio de Janeiro Fortense Universitária, 2000.

MCLUHAN, M. Os meios de comunicação: como extensões do homem. Editora Cultrix, 1974.

MCNEAL, J. U. et al. Children as consumers of commercial and social products. Washington, DC: Pan American Health Organization, 2000. 
MINAYO, M C. de S. et al. Pesquisa social: teoria, método e criatividade. Vozes, 2013.

MIRANDA, V. da C. et al. Como consentir sem entender?. Rev. Assoc. Med. Bras. [online]. 2009, vol.55, n.3, pp. 328-334. ISSN 1806-9282.

MOTTA, F. C. P. Desenvolvimento e meio ambiente: as estratégias de mudanças da agenda 21. Rev. adm. empres., São Paulo, v. 38, n. 2, p. 74-75, June 1998.

OLIVEIRA, T. M. V de. Amostragem não probabilística: adequação de situações para uso e limitações de amostras por conveniência, julgamento e quotas.

Administração on line, v. 2, n. 3, 2001.

POSTMAN, N. O Desaparecimento da Infância. Rio de Janeiro: Graphia Editorial, 2002.

PRODANOV, C. C; FREITAS, E. C. DE. Metodologia do Trabalho Científico:

Métodos e Técnicas da Pesquisa e do Trabalho Acadêmico. $2^{\circ}$ Ed. Feevale, 2013.

REIS, E. (1996). Estatística descritiva. Lisboa: Edições Sílabo.

ROCHA, E; RODRIGUES, J. Corpo e consumo: roteiro de estudos e pesquisa. Rio de Janeiro: PUC/RJ, s/d.

SAMPAIO, R. O Maslow desconhecido: Uma revisão de seus principais trabalhos sobre motivação. Revista Administração. São Paulo, v. 44, n.1, p. 5 - 16, 2009.

SANTAELLA, L. Cultura e artes do pós-humano: da cultura das mídias à sibercultura. $4^{\circ}$ ed. São Paulo: Paulus, 2003.

SANTOS, G. E. de O. Cálculo amostral: calculadora on-line. Disponível em: <http://www.calculoamostral.vai.la>. Acesso em: 20 jun. 2015.

SANTOS, J. M. Teorias da comunicação. Universidade da Beira Interior, 2004.

SECRETARIA de Comunicação Social, Pesquisa brasileira de mídia 2015: hábitos de consumo de mídia pela população brasileira.-Brasília: Secom, 2014 Disponível em:<http://www.secom.gov.br/atuacao/pesquisa/lista-de-pesquisas-

Ciência e Sustentabilidade - CeS | Juazeiro do Norte v. 2, n. 1, p. 56-81, jan/jun 2016 
quantitativas-e-qualitativas-de-contratos-atuais/pesquisa-brasileira-de-midia-pbm2015.pdf.>Acesso em 18 de abril de 2015.

SERRA, P. Proximidade e Comunicação. In: SANTOS, José Manuel. Teorias da comunicação. Universidade da Beira Interior, 2004.

SOLOMON, M. R. O comportamento do consumidor: comprando, possuindo e sendo, 9. ed. Porto Alegre: Bookman, 2011.

TRIVIÑOS, A. N. S. Introdução à pesquisa em ciências sociais: a pesquisa qualitativa em educação. Atlas, 1987.

TUBELLA, I. Televisão e internet na construção da identidade in: Castells, Manuel; Gerhardt, Klauss Brandini. A sociedade em rede. São Paulo: Paz e terra, 2000.

VYGOTSKY, L. S. A formação social da mente. Ed.7 São Paulo - SP: Livraria Martins Fontes Editora Ltda. 2007.

ZANELLA, L. C. H. Metodologia de estudo e de pesquisa em administração. Florianópolis: Departamento de Ciências da Administração/UFSC, 2009. 